\title{
Las máquinas de la familia ${ }^{1}$
}

\author{
Josep-Antoni Ybarra (Universitat d’Alacant, Alacant, Espanya)
}

\section{Cita bibliográfica: Ybarra, J.-A. (2021). Las máquinas de la familia. Disjuntiva, 2(2), 106-111.}

https://doi.org/10.14198/DISJUNTIVA2021.2.2.7

Aún no se lo he dicho a mi abuela ni a mi madre. Imagino que cuando les diga que voy a empeñarme y comprar un buen ordenador para quedarme a trabajar en casa, se acordarán de sus máquinas, la de aparar ${ }^{2}$ y la de escribir. En esas máquinas está la historia de sus vidas, la historia de mi familia. Es posible que con el ordenador que compre, continúe la historia de la familia. Si bien espero que ahora la historia sea distinta.

Lo había oído muchas veces; daban las noticias de la 1:00 de la madrugada; ella seguía enganchada a la máquina. Debía entregar la faena al día siguiente por la mañana. A las 9:00 pasaría el repartidor otra vez. Éste tenía dicho que dejaría una partida de sesenta pares de botas pero tenía que recoger los cien pares de sandalias que estaban haciendo y que eran urgentes. Las sandalias, fáciles de hacer, pero poco rentables aun haciendo muchas; y había que acabarlas esa noche, aunque fuera a las tantas de la madrugada y aunque se estuviesen recortando aún los hilillos que sobresalían después de pespuntearlas con la máquina. La abuela lo decía, "cuando traen sandalias, la hora sale a menos de diez duros". Total, tenía que trabajar más de 50 horas a la semana para sacarse un jornal medio decente; decía que era preferible aparar botas, bluchers ${ }^{3}$ o si acaso kiowas, para que cundiesen más las horas y así sacar 500 ptas. más a la semana. Así se trabajaba menos y se ganaba más. Aunque eso sí, la casa siempre la tenía llena de bolsas con cortes, forros y pieles, y con olor a cola, a cemen ${ }^{4}$, a pegamento; todo el día detrás de la faena; con la máquina metida en la cocina o en el comedor; con el run-run del motor de la máquina golpeando en la cabeza; y eso un día tras otro, sin vacaciones ni fiestas de guardar, pero siempre pendiente de la faena que trajeran para entregar urgente al día siguiente. Se trabajaba cuando había trabajo; cuando no traían faena, pues no se trabajaba.

Esa fue la rutina de la abuela desde que se casó hasta que dejó de trabajar cuando tenía casi los setenta. Al principio fue distinto cuando trabajaba en la fábrica. Allí tenía un horario fijo, una máquina fija, un puesto fijo; iba a destajo también, pero dentro de la fábrica. Después de batallar mucho, se compró su máquina para trabajar, aparando, en su casa. Se lo pensó mucho; dudó mucho; fue antes de casarse, pero al final lo hizo. Estuvo pagando cuarenta duros semanales (toda una fortuna para la época) hasta que después de año y medio, la máquina fue suya. Y así fue como "se

1. Texto presentando al III Certamen Literario "El Trabajo en la Historia" bajo el seudónimo Jacinta Gomara Dallo; certamen convocado por La Fundación Francisco Largo Caballero, en colaboración con la Universidad de Alcalá y el Ayuntamiento de Alcalá de Henares; mayo 2021.

2. La "máquina de aparar" es la que se utiliza para unir, cosiendo, las piezas sueltas que componen un zapato. Estas piezas son de cuero o plástico. Las personas que realizar esta actividad suelen ser mujeres, y por ello el término familiar que se utiliza en el sector del calzado es el de "aparadora", en femenino. No obstante, antes de la guerra civil española también había hombres que realizaban esta actividad.

3. Bluchers o kiowas son tipos de calzado.

4. Cemen es un tipo de pegamento especial utilizado para unir piezas de cuero o plástico del calzado que utilizan las aparadoras. En lenguaje coloquial se suele valencianizar el termino llamándolo "semen”, la 'c', se sustituye por una 's' líquida.

Correo electrónico de correspondencia: ybarra@ua.es. 
dejó la fábrica". Tendría entonces veinticuatro o veinticinco años; se casó y se dejó la fábrica. Su regalo de boda fue irse a trabajar a su casa con su máquina. ¡Menudo regalazo! Y se llevó a su casa la faena que antes hacía en la fábrica, si bien entonces iba a trabajar por partida doble.

En casa hacía lo mismo que en la fábrica, pero además tenía que hacer todo lo de la casa: fregar, comprar, cocinar, lavar, cristales, ropa, etc., y encima cuando tuvo a la chiquilla -a mi madre-, ocuparse de ella. ¡Toda una emancipación! Y eso lo hizo porque quiso. En la única fábrica que trabajó, El Zapato de Oro, estuvo trabajando desde que tenía catorce años, desde que su padre la llevó por primera vez a la fábrica para ayudar. Y de ayudanta, al cabo de año y pico, la pasaron a aprendiza, ya con su cartilla del seguro y todo, y ya después, de aprendiza estuvo un par de años, y la pasaron a ocupar un puesto como aparadora fija de la empresa. Eran más de cuarenta las aparadoras que había; todas con seguro; todas con puesto fijo. En aquella fábrica, en aquellos años, trabajaban más de doscientos trabajadores. Había dos naves en las afueras del pueblo, aparte de las oficinas que estaban en el centro de la ciudad. Una nave era de producción donde estaban las secciones de cortado, aparado, montaje y la envasa ${ }^{5}$ y la otra nave hacía de almacén, donde estaban todos los materiales, las hormas que no gastaban, las pieles y la faena acabada y envasada. En la fábrica había desde servicio de incendios hasta una barbería para los hombres; tenían economato y practicante de la empresa y todo. ¡Qué cosas!, eso ahora no se si existe en alguna fábrica de calzado.

El abuelo, por su parte, trabajaba en La Unión Zapatera, otra de las empresas grandes de calzado que había en el pueblo. Esta empresa había nacido de la unión de varias que hacían lo mismo -de ahí el nombre que le habían puesto-, porque un señor viajado y conocedor de lo que pasaba por el mundo, había visto que era mejor que las pequeñas empresas se unieran. Así sacarían zapatos a costes más reducidos y tendrían de esta manera más trabajo y beneficios. Este señor, el Sr. Avelino, que como signo de distinción social, decía el abuelo, siempre fumaba puros, propuso a las fábricas pequeñas, que hasta la fecha competían entre sí, que se unieran; de esta manera, uniéndose no competirían las unas con las otras y hasta podrían pactar precios. Entonces lo que importaba era, según comentaba mi abuelo, que cuanto más grande fuera la empresa, más baratos salían los zapatos. La fuerza y la ventaja de las empresas residía en lo grandes que éstas fueran. Y grandes empresas, como eran La Unión Zapatera o El Zapato de Oro, hacían gran cantidad de zapatos, muy parecidos, por no decir iguales, baratos, que iban a satisfacer una demanda creciente de gente que dejaba de andar con alpargatas y comenzaba a calzar zapatos, botas y sandalias de todo tipo.

Momentos aquellos en que había trabajo, mucho trabajo; ello comportó empleo en las fábricas y en las casas. La gente venía al pueblo de otros lugares para trabajar aquí. El pueblo era la Alemania y la Suiza del momento. En el pueblo era bienvenida cualquier persona y cualquier familia que tuviese ganas de trabajar, con la ventaja de que estas personas no tenían que irse al extranjero, tan lejos, sin cambiar de idioma, sin dejarse a la familia y a los hijos. Había trabajo y se necesitaba gente para trabajar. Estos forasteros que llegaban eran la salvación. Las máquinas de aparar como las de mi abuela, primero en la fábrica y después en las casas, trabajando para aquellas grandes fábricas, no hacían otra cosa más que aparar y aparar pares de zapatos. Y así, mayoritariamente los hombres en las fábricas y las mujeres en sus casas sacaron adelante a sus familias. Además, muchas mujeres, como la abuela, criaron a sus hijos en sus casas trabajando día y noche.

El seguro y el médico que tenía mi abuelo en su fábrica eran el seguro y el médico que cubría a toda su familia. Como él y mi abuela, es lo que hacía todo el mundo. La escuela del barrio era la escuela para toda la familia y todo el barrio. La tienda de ultramarinos, en la plazoleta del barrio, era el súper del momento con la particularidad de que fiaba entresemana, hasta que se cobraba el sábado a mediodía, y entonces se le pagaba las deudas que se hubieran contraído a la largo de la semana. Y el piso que se compraron los abuelos; pequeño; un cuarto sin ascensor; en él casi no entraba el sol; hipotecados hasta el cuello, lo pagaron poco a poco con el trabajo del abuelo y de la abuela, en parte con el esfuerzo de aquellas noches sin dormir aparando los cientos y cientos de botas, sandalias, bluchers y kiowas que el repartidor de la fábrica le dejaba por las mañanas. Algunas de aquellas noches tenía que trabajar todo el mundo en casa porque era una partida más grande de lo habitual, y como siempre urgente, había que entregarla al día siguiente a primera hora; y allí estaba la abuela, el abuelo, mi madre, mi tío y hasta alguna vecina para tirar una mano. La radio y la estufa de gas, en el salón-comedor o en la cocina de la casa, calentaban y amenizaban las veladas hasta altas horas de la madrugada.

Y así pasó el tiempo. La abuela dejó de trabajar en casa casi con setenta años. Sin pensión, con una atrofia en las manos y una desviación en la espalda; tomando siempre ibuprofeno y paracetamol como quien toma pan y agua a diario para poder olvidarse de los dolores de espalda y de las manos. Fue todo lo que le quedó de aquel regalo que se hizo antes

5. La envasa se refiere a la última fase del proceso de producción, aquella que trata de enlucir el zapato acabado y ponerlo en cajas para su posterior comercialización. 
de casarse cuando era joven: la máquina de aparar. El tiempo que estuvo trabajando en la fábrica y que había cotizado a la Seguridad Social no le fue suficiente para que le reconociesen pensión alguna. El trabajo que siempre hizo en casa era trabajo no reconocido y perdido para su vejez. Aunque nunca estuvo sindicada, fue a los dos sindicatos a informarse de sus posibles derechos; los dos abogados le dijeron lo mismo: "la ley es muy clara en esto, si has cotizado, tienes derecho, si no, no puedes reclamar nada”.

Por su parte, mi madre se enseñó también a aparar. Lo tenía muy fácil. Ayudaba a su madre, a mi abuela, por las noches, los fines de semana y siempre que hacía falta. La máquina la tenía a su disposición. Su madre era la maestra; no necesitaba cursos especiales. Bastaba con ponerse delante de ella y hacer lo mismo de forma repetida una y otra vez. La necesidad obligaba a trabajar a destajo para poder pagar la hipoteca del piso, además de la compra semanal en el súper de la plazoleta. La cosa estaba clara: mi madre acabaría como mi abuela, trabajando en casa.

Sin embargo ocurrió algo imprevisto. En la escuela del barrio, mi madre se enseñó a leer y a escribir rápidamente. Era algo que a mis abuelos les sorprendió. Ellos leían y escribían con dificultad. A pesar de ello, mi madre en Las Graduadas, en aquella "escuela nacional” que había en el barrio, se enseñó las cuatro reglas con rapidez y parecía que necesitara conocer y saber más cosas. El maestro les dijo a mis abuelos que mi madre aprovechaba para estudiar algo más que las cuatro reglas. La decisión entonces era difícil de tomar: estudiar o trabajar. ¿Cómo iba a estudiar la hija de un zapatero y de una aparadora? ¿Lo normal no sería continuar siendo aparadora? El dilema se solucionó pronto; se arregló a medias ya que lo que pasó fue que mi madre compatibilizó las dos cosas: estudiaba en la escuela por las mañanas a la vez que trabajaba por las tardes y noches ayudando en casa a mi abuela con la máquina de aparar.

El tiempo pasaba, y así poco a poco se fueron despejando las cosas. Y no era por el falso orgullo, o quizás por la excesiva sencillez que para ella significaba ser aparadora, sino por la pretensión de superarse como persona. Y así fue una combinación de circunstancias: primero la abuela y su tajante postura al insistir que "de esta forma, con estudios, alguien de la familia podía dejar de ser una mula deslomándose delante de la máquina”; y la otra circunstancia fue la influencia del novio de mi madre, mi padre, cuando aún no se habían casado. Mi padre, jovencito, era un recién llegado, venido al pueblo con sus padres, mis abuelos paternos -los llamados "forasteros" como inmigrantes que eran-. La influencia de mi padre sobre mi madre fue a todas luces decisiva ya que le metió en la cabeza la idea de mejorar su situación. Se conocieron en la escuela del barrio, en Las Graduadas; mi padre decía que ella -mi madre- sobresalía en mecanografía y en temas relacionados con los números, mientras que él era conocido por ser un gran hablador. Estas cualidades había que aprovecharlas entonces. ¿Cómo? Fácilmente. Mi madre podría pensar en emplearse en algún sitio como secretaria; él podía valer para vender, aprovechando su palabrería. Sería la forma de progresar, de poder superarse en la vida. Mi padre trasmitió a mi madre, aun siendo novios, aquella idea que tantos inmigrantes tenían en su ADN: progresar y mejorar frente al lugar de origen que pudieran tener. Y esta idea significaba en el caso de mi madre que debía olvidarse de la máquina de aparar y pensar en una máquina de escribir; sería su progreso; era salir de las tardes y noches delante de la máquina de aparar y buscar en la calle alguna empresa, o algún sitio, donde necesitaran a alguien que supiese escribir a máquina. Sus estudios se centraron básicamente en una serie de ejercicios de mecanografía y taquigrafía, a la vez que en temas relacionados con cálculo mercantil y administración. Y así fue como mi madre encontró trabajo de secretaria en una oficina; era una buena organizadora y administrativa, y por supuesto, era muy buena mecanógrafa. Pasó por tres o cuatro empresas y despachos. En todos, según dice, era recordada por su competencia y destreza.

Aunque ella había trabajado en casa desde bien pequeña ayudando a mi abuela, empezó a cotizar cuando la contrataron por primera vez en la oficina de una pequeña empresa de fabricación de suelas para calzado. Allí llevaba la administración y la contabilidad de la empresa. En realidad, el que la enseñó a llevar la contabilidad fue un señor que trabajaba en el banco. Este señor, por las mañanas estaba en el banco, y por las tardes iba de empresa en empresa, todas pequeñas, a llevar contabilidades. Era un experto en asentar facturas y ajustar balances. Y de él mi madre se enseñó realmente contabilidad y administración. Al final era ella quien, en aquella empresa de suelas, llevaba la contabilidad, pero a la vez, toda la oficina: bancos, proveedores, compras, facturación, clientes, y todo lo que le viniera encima. Fue la forma de ir superándose en el día a día.

Resultó además que, en aquel momento, dos de las grandes fábricas del pueblo entraron en crisis y despidieron a mucha gente. Esta gente despedida lo que hizo fue cobrar durante un tiempo el derecho al paro y montar a la vez pequeños talleres para hacer lo mismo que estaba haciendo en la fábrica. De este modo, el campo, los alrededores de la ciudad, los garajes, los almacenes y cualquier espacio se convirtieron potencialmente en pequeñas fábricas donde se hacía lo mismo que anteriormente se estaba haciendo en la gran fábrica. Fue una descentralización de la cadena de producción del sector del calzado, en la que el trabajo de la fábrica se desintegró y se esparció bajo el lema "sálvese quien pueda”. La gente que sí tenía oficio, que sabía hacer zapatos, suelas, cortar, rebajar, aparar, montar, desvirar, y hacer algo en cualquiera de las fases de un zapato, siguió haciéndolo. La diferencia era que ahora ellos, los trabajadores expulsados de las grandes fábricas, eran sus propios jefes en aquellos pequeños talleres. Incluso había alguna cuestión de mayor 
calado como fue el hecho de asumir que los ritmos de trabajo ahora, de forma autónoma, serían mucho más intensos que cuando trabajaban en la gran fábrica. Además ocurrió que muchos pasaron a trabajar sin contratos y sin seguridad social, perdiéndose derechos que tanto había costado que se reconocieran. De esta forma, los nuevos organizadores de la cadena descentralizada no se responsabilizaban de lo que los trabajadores, ahora autónomos, estaban haciendo para poder subsistir, que era sencillamente trabajar. El empleo de las fábricas estaba desapareciendo y simplemente se transformaba en trabajo intensivo hecho ahora de forma dispersa y sin seguridad. La gran transformación de la organización productiva fue espectacular, con gran impacto tanto para la economía como para la gente; de la seguridad del empleo en la gran fábrica se pasó a la incertidumbre del trabajo disperso y del búscate la vida. Los sindicatos trataron de taponar esta hemorragia pero era imposible, no había forma de parar la desintegración del sector.

Esta situación hizo que mi madre saltara de un trabajo a otro de forma continuada y rotativa, siempre en aquellas pequeñas empresas fruto de la descentralización que estaba produciéndose en el sector del calzado. Valoraban su destreza para llevar las cuentas y la administración, así como sus dotes organizativas para mejorar cualquier negocio. Esto le hizo cambiar de empleos en una situación como la descrita, en que la celeridad en la aparición y desaparición de empresas era fruto de la situación de profundas reformas que se estaban produciendo. Igual le ocurrió a mi padre, que pudo encontrar sucesivamente trabajo de representante, primero de pieles, después de cajas de cartón y ya por fin de chicarro -calzado de bebé y niño-; era el oficio del gran hablador que trataba de sobrevivir con sus cualidades verbales.

Como forma peculiar de contratación de este numeroso ejército de trabajadores que había quedado expectante después del hundimiento que estaban sufriendo las grandes empresas, fue algo que se generalizó de forma desmedida en el sector: es lo que popularmente se llamó "contrato rotatorio". Este contrato rotatorio no es que fuese querido, sino que era el único al que tenían opción muchos de los trabajadores despedidos de las grandes empresas y contratados ahora por aquellas pequeñas empresas que sobrevivían. Consistía este contrato en que los derechos de prestaciones sociales y laborales que un contrato puede tener en un año, se repartían entre 3 o 4 trabajadores de forma que rotativamente, cada trimestre, uno de estos cuatro trabajadores tenía los derechos formales y el resto no, aunque estuviesen trabajando. En realidad los trabajadores no dejaban de trabajar en el mismo lugar y en la misma empresa, pero el contrato legal rotaba a lo largo del año entre 4 personas. La empresa tenía un contrato por el cual cotizaba, y este contrato rotaba entre 4 trabajadores. Era un fraude conocido y consentido, que el trabajador no tenía otra opción que asumir, de lo contrario siempre existía la frase "y si no te gusta, ahí está la puerta". Las acciones sindicales se centraron en denunciar estas situaciones, pero la reacción real persistía en la práctica descrita. Las inspecciones de trabajo existían, pero fueron insuficientes para hacer frente a la generalización que tuvo la práctica referida. Esta inseguridad laboral es con la que sobrevivió mi madre durante algún tiempo aceptando contratos rotativos o trabajando sin contrato a pesar de sus destrezas y de sus conocimientos. Por parte de mi padre exactamente igual.

Y en esta situación de inestabilidad y con cerca de treinta años que iba a cumplir mi madre, decidieron casarse. ¿Y qué mejor regalo de boda se le podía hacer? ¿Por qué no una máquina de escribir eléctrica, de las buenas? Era su herramienta de trabajo allá donde trabajaba, y quién sabe si en un futuro no se arreglarían las cosas y la iba a necesitar. Y poco se equivocaron estos pronósticos, porque al poco mi madre quedó embarazada, y según pensaron, para mejor bienestar de sí misma y del futuro bebé, ella dejaría de buscar trabajo en la calle con o sin contrato. Se tomaría un período de descanso -después de toda la vida trabajando- y se podría intuir que, dada su competencia y pericia, cuando quisiera volver a trabajar, algo encontraría. Mientras, con la máquina en casa, podría hacer alguna cosa.

Y así de pronto, después de más de diez años de experiencias laborales intensas, mi madre se encontró en casa con una flamante máquina de escribir eléctrica y con una niña en sus brazos -la niña era yo-. Había pasado otra vez lo mismo que con la abuela: la mujer, en este caso mi madre, había vuelto de la empresa a la casa, haciéndolo de forma voluntaria, encontrándose con una máquina para trabajar y un bebé que cuidar. En realidad poco habían cambiado las cosas.

Después de nacer yo, nació mi hermano y aquello condicionó aún más la vida laboral de mi madre. Sí, hacía alguna cosa en casa con su máquina de escribir eléctrica; pasar algunos escritos a máquina de gente de la universidad que necesitaba cosas para sus artículos y sus trabajos, también algunas cartas para despachos de abogados y arquitectos, pero poca cosa más. También se puso a vender en alguna ocasión artículos de belleza a domicilio (cremas y jabones para la cara), y tupperwares y ollas. Para vender hacía reuniones en casa y en casa de amigas y vecinas. Quería ganarse la vida, pero ya nunca fue como antes. El empleo se había ido, el trabajo era escaso, el oficio no tenía utilidad, y solo quedaba la inseguridad del momento. Pero siempre lo repetía, ¿y si volviera a aparar? ¿Por qué no podía volver a la máquina de la abuela?

Sin embargo, la realidad es que nunca lo hizo aunque mi abuela le había dado la máquina de aparar. En verdad, mi madre tenía aquella máquina como una pieza de museo en la entrada del piso que mi padre y ella se habían comprado hipotecándose también hasta los ojos. Un piso en las afueras del pueblo; piso que formaba parte de una de las seis torres de diez plantas cada una, que en el viejo solar de la fábrica que fue El Zapato de Oro habían construido. Su dueño había 
convertido la fábrica en solar, y de solar pasó a construir pisos. Había pasado de ser fabricante de calzado a ser promotor de pisos. ¡Menudo negocio había conseguido con ello! Este señor sí supo entender lo que significó aquello del Plan de Reconversión del Calzado; Plan que ingenuamente se pensaba por parte de los trabajadores iba a representar la tabla de salvación para muchos, pero en realidad tan solo sirvió para enriquecer a aquellos que tenían el poder y la capacidad económica para llevarlo a la práctica, tal fue el caso de esas grandes empresas. En realidad aquella reconversión consistió en deshacerse de las obligaciones y de la plantilla de la fábrica, construir pisos en su lugar y convertir su empresa en una comercial. Con esta comercial se haría de intermediario, comprando los zapatos a los talleres y pequeñas fábricas, y vendiéndolos en el extranjero a los que eran sus antiguos clientes; y todo ello sin ningún tipo de obligación contractual con los trabajadores ni con nadie. Aquella reconversión animó a los empresarios, la legislación se lo permitió e incluso se les subvencionó en alguna ocasión.

La destrucción del viejo sector estaba cantada; sus formas tradicionales de producir y de organizarse quedaron obsoletas frente a la flexibilidad y fluidez que ofrecían las pequeñas unidades que canalizaban su trabajo hacia las comercializadoras dirigidas ahora por sus antiguos dueños o por sus herederos. Las cosas habían cambiado drásticamente, la rentabilidad que tenía la gran empresa hacía un par de décadas ahora estaba en aprovecharse de la pequeña empresa y del esfuerzo de esta dispersión. Se hizo lo que reza el refrán: ¡o renovarse o morir! Y eso fue lo que ocurrió, se murió parte del sector, y se renovó otra de sus partes. En este proceso de reconversión, lo que quedó finalmente fue un nuevo paisaje en el que sobresalían muchos viejos trabajadores condenados al desempleo, y los nuevos, sumisos a condiciones precarias, trabajando en cadenas de talleres y de microempresas que a su vez están enlazadas con comerciales, vinculadas a las grandes cadenas que manejan el mundo comercial y el consumo; una adaptación local a la globalización. La realidad de la reconversión es que el empleo se perdió, el trabajo se degradó y el oficio se olvidó.

Fueron momentos duros para muchos, para la mayoría de los que conocían el sector, el trabajo y su oficio. Día tras día aparecía la noticia de que alguna empresa estaba en suspensión de pagos, había cerrado sus puertas, y un número indeterminado de trabajadores pasaban al paro. Y por ahí pasó mi padre, pero en realidad fue como si hubiera pasado toda la família. Mi madre ya la había pasado antes, hacía unos años; ella no estaba implicada directamente en el sector en estos momentos, pero sí que pasó por ello indirectamente porque una situación como la que se presenta la viven todos los miembros de la familia. La verdad es que fue duro; difícil de soportar porque en realidad te quedas sin saber qué puede pasar con el futuro, ya no solo por parte del sujeto que se queda parado, sino de todos aquellos que pueden depender o tener relación con ese sujeto: hijos, mujer, parientes, amigo, vecinos, etc. La ansiedad, la inseguridad, el temor, la incertidumbre, son elementos que se vienen encima de uno. Se piensa en lo incapaz e inútil que uno -el parado- puede ser. La depresión fue el estado habitual en que se encontraba mi padre parado. La idea que pasaba por la cabeza de mi padre era la de que su inactividad se debía a su torpeza e inutilidad. ¡Terrible la situación en la que cae un parado, en la que no solo aparece la depresión, sino que llega a sentirse culpable y responsable de su propio paro!

La entereza de mi madre fue lo que nos salvó. Animaba todos los días y a todas horas a mi padre que estaba hundido. Y nosotros, mi hermano y yo, pasamos casi de puntillas sobre aquellos problemas que día a día se planteaban de cómo pagar las facturas del agua, la luz, el gas, la gasolina del coche, las compras en el súper, etc. Lo más grave era pagar la hipoteca mensual. Muchas veces fueron mis abuelos los que arrimaron el hombro y pusieron parte de la cuota que había que pagar.

Nos acostumbramos a vivir en el día a día. Mi padre, igual que mi madre, unos días tenía trabajo y otros no, unos días vendía una cosa y otros no, y así íbamos tirando. Ella con sus ollas y jabones; él iba pasando de una comercial a otra, tratando de vender unas veces coches, otras embutidos y otras bebidas. Como siempre le pagaban a comisión, e incluso en alguna ocasión con los mismos productos que iba vendiendo (tal fue el caso de una remesa de detergentes para lavadoras, que los tuvimos que vender nosotros -toda la familia- porque no nos cabían en nuestra propia casa y era el pago que le habían hecho a mi padre por haber trabajado para esa casa de detergentes durante un tiempo); aquellas cajas de detergentes las vendimos en el barrio y en el vecindario; curiosamente casi todo el barrio compró detergente.

Por mi parte, estaba acostumbrada a trabajar de camarera los fines de semana en el bar de un amigo de mi padre que había abierto después de que le cerraran la fábrica -su reconversión fue de zapatero a barman, y todo en dos meses, hasta que tuvo todos los permisos del bar-. En aquel bar, que recalentaba productos ya hechos de Mercadona y del Cash \& Carry, me sacaba un dinerillo; ello me permitía ir tirando de las cuatro cosas que necesitaba: bus, ropa de segunda mano, tabaco, música, teléfono, algún perfume y poca cosa más. Lo que hacía durante la semana era ir a la Uni. Esto era lo que mi madre se empeñó que hiciera. No quería que trabajara en nada relacionado con el zapato. Ni aparadora, ni contable, ni nada de nada. “¡Olvídate de cualquier cosa que huela a zapatos!” me decía. Era la orden continua que salía de la boca de mi madre. Y así lo hice.

Y como yo no era mala en mates, en la Uni me apunté a Informática. Me dediqué a ello compatibilizando con los fines de semana en el bar, y por fin saqué la carrera. No está nada mal. En cinco años me planté con el título en casa. 
Todo un orgullo para todos. La nieta de la aparadora, la hija de la mecanógrafa, ahora era toda una informática: la carrera de la que todo el mundo hablaba como la carrera del futuro. ¿Qué hacer entonces?

La vida laboral empezó entonces para mí. Comenzaba a diseñarse mi mundo, mis esperanzas, mis deseos..., y también mis frustraciones. Pasé de becaria a mileurista sin llegar a percibir ni siquiera esa cantidad. De mileurista a autónoma, y de autónoma a cooperativista de una empresa formada por cuatro excompañeros de la Uni que nos habíamos metido a eso de "emprendedores". Todo ello en la friolera de año y medio. Los cambios se sucedían rápidamente porque se agotaban los contratos, los proyectos, y las esperanzas desaparecían de un día para otro.

Ahora es cierto que estoy un poco más tranquila porque me han ofrecido la posibilidad de trabajar desde casa, trabajo on line, como autónoma, para una empresa de calzado, una comercializadora exactamente. Esta necesita datos para saber cuánta gente entra en su página web a ver sus catálogos, y también saber desde diferentes plataformas las visitas y los perfiles de los productos más vistos. Esto que desde la informática llamamos trabajar con BigData. Lo cierto es que estoy dispuesta a empeñarme y comprar un ordenador más potente del que tengo actualmente -una máquina mejor- para llevármelo a casa y trabajar desde allí.

La verdad es que no se lo he dicho aún ni a mi abuela ni a mi madre. No sé si me dirán que la historia se repite, pero la verdad es que no tengo otra opción por ahora. Volver a la casa cargada de una máquina para poder sobrevivir con mi trabajo desde allí. Bien, espero que al menos esta vez pueda tener la autonomía para poder elegir y trabajar con dignidad. Sería un paso que permitiría decir que algo se ha avanzado en la historia de la familia. 